\title{
DEMOGRAPHIC ANALYSIS ON THE MONORAIL AND URBAN DEVELOPMENT
}

\author{
Yuan wen Zhang, Fukuda Hiroatsu, and Yu peng Wang* \\ Faculty of Environmental Engineering, The University of Kitakyushu, Kitakyushu, Japan \\ * Corresponding author (m10e2201@hibikino.ne.jp)
}

\begin{abstract}
Nowadays, typical cities are heavily reliant on automobile cars. which makes the public services inefficient and cities are becoming hollowed out, in this case, cities gradually lose vitality. This study is about the problem which is based on the population alongside the Kitakyushu monorail, people there are looking forward to resolving this issue. In order to learn the situation of the urban development of Kitakyushu alongside the monorail, we conduct a survey in the form of a questionnaire on the population who lived and used the monorail.
\end{abstract}

Keywords: Monorail, Usage Situation, Population, Urban Development

\section{BACKGROUND}

The Kitakyushu monorail is a monorail in Kitakyushu, Fukuoka, Japan, run by the Kitakyushu Urban Monorail Co. Ltd. (Kitakyushu Kosoku Tetsudo Kabushiki gaisha, literally "Kitakyushu High Speed Railway Co. Ltd.").

The Kokura Line (Kokura sen) is currently the only line. It runs the $8.8 \mathrm{~km}(5.5 \mathrm{mi})$ between Kokura station and Kikugaoka station in Kokura Minami ward in about 18 minutes. It was opened on January 9, 1985 between the station now called Heiwadori and Kikugaoka, and extended about 300 metres (1000 ft) to Kokura station from Heiwadori on April 1, 1998.

The monorail is owned by the city of Kitakyushu, and did not begin to make a profit until the extension to Kokura station was completed. This had been resisted by the businesses in Uomachi shopping district who feared they would lose customers, but that did not happen.

Once a year there are beer parties and wine parties held on the monorail, bookings made in advance. Santa Claus boards the train on December 24.

There is apparently no plan to build a new line or extend the existing one at this time.
Nowadays, typical cities are heavily reliant on automobile cars. which makes the public services inefficient and cities are becoming hollowed out, in this case, cities gradually lose vitality. This study is about the problem which is based on the population alongside the Kitakyushu monorail, people there are looking forward to resolving this issue. In order to learn the situation of the urban development of Kitakyushu alongside the monorail,we conduct a survey in the form of a questionnaire on the population who lived and used the monorail.

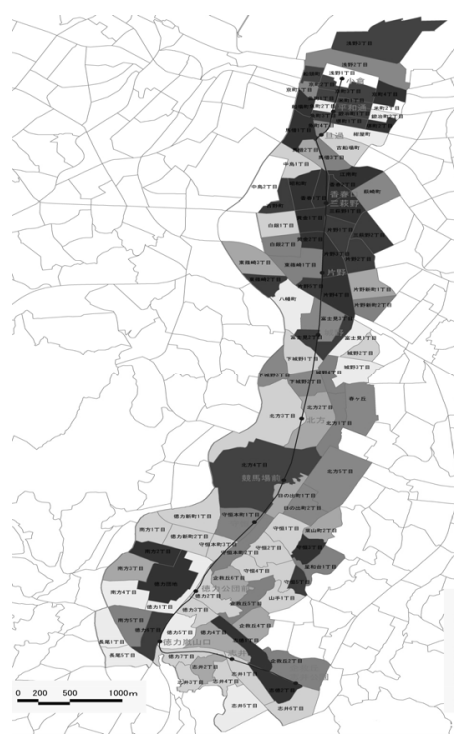




\section{Analyses on the Result of Questionnaires}

\subsection{A home address}

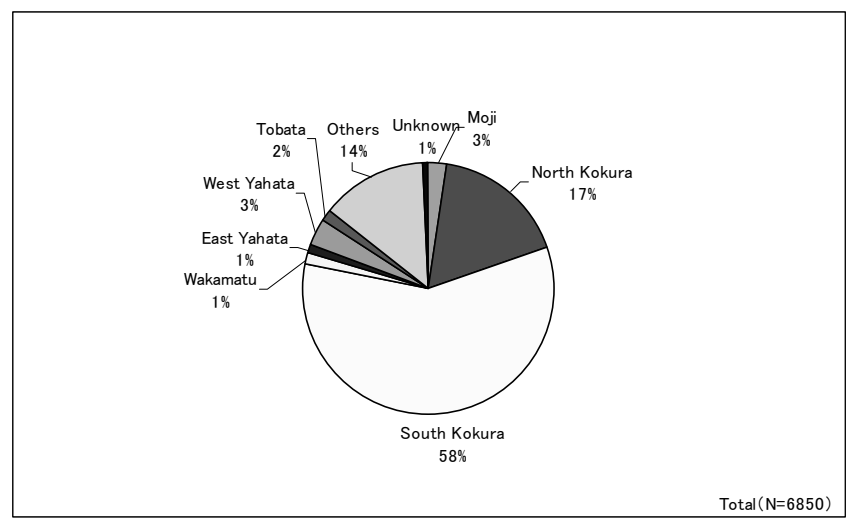

Fig.1 Home address

About users 'residencies, the south part of Kokura accounted for more than half $58 \%$, which is actually the north part of Kokura, accounted for $17 \%$

\subsection{The kind of the tickets}

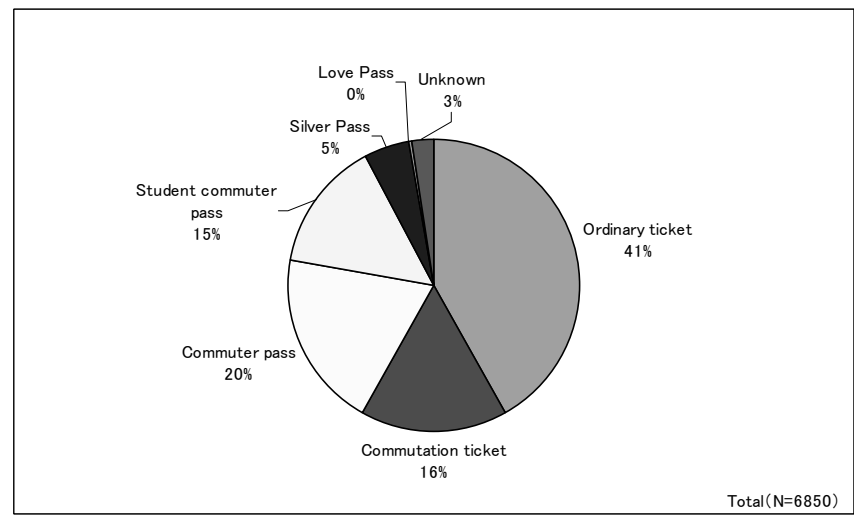

Fig.2 The kind of the tickets

Judging from tickets' types of the users, ordinary ticket accounted for $41 \%$, work commutation ticket occupied $20 \%$, commutation tickets accounted for $16 \%$ commutation tickets for students accounted for $15 \%$, go to work or school accounted for $35 \%$ of all the commutation tickets.

\subsection{The purpose of monorail's usage}

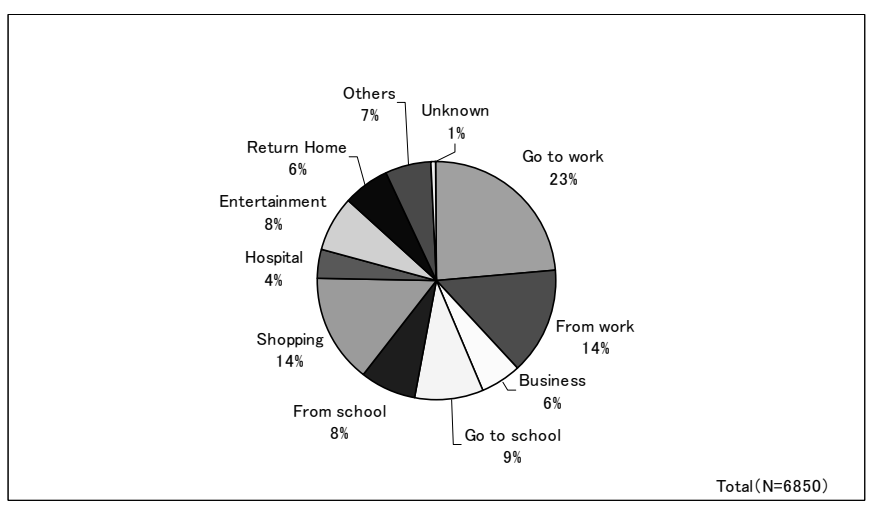

Fig.3 The purpose of monorail's usage

On the users' purposes, working accounted for $23 \%$, $14 \%$ from work, commuting accounted a total of $37 \%$. Second, $14 \%$ go shopping, go to school and from school accounted a total of $17 \%$.

\subsection{The transportation from home to monorail Station}

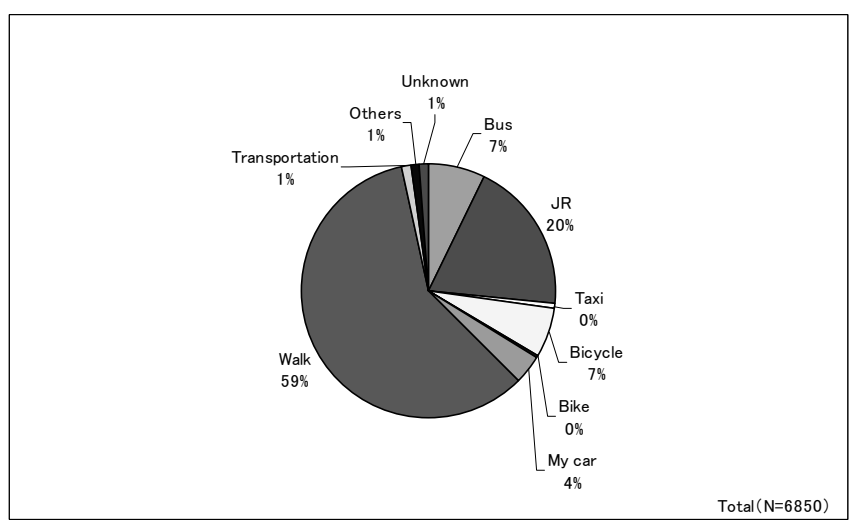

Fig.4 The transportation from home to monorail Station

The transportation from home to monorail Station, walking accounted for $69 \%$, followed by JR, $20 \%$, bicycles and buses accounted for $7 \%, 4 \%$ are private cars.

\subsection{The gender of the users}

Considering the users' gender, women accounted for $62 \%$ and men $37 \%$, the proportion of women is more than 
men by $25 \%$.

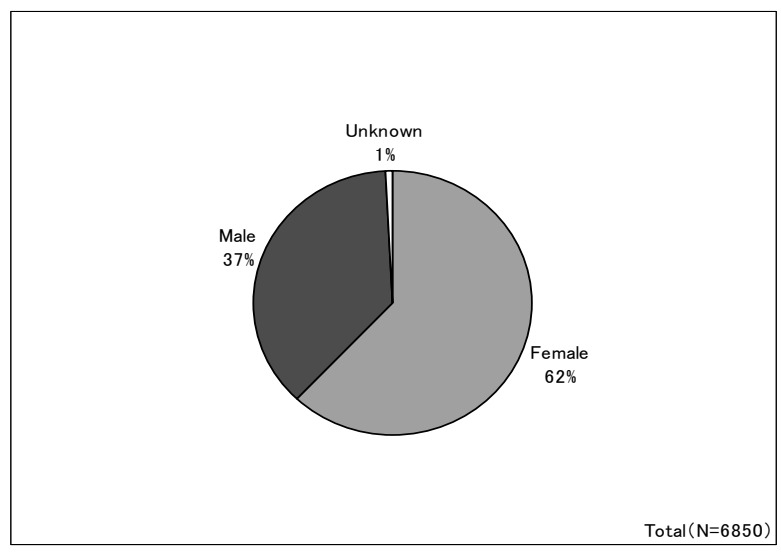

Fig.5 The gender of the users

\subsection{The age of users}

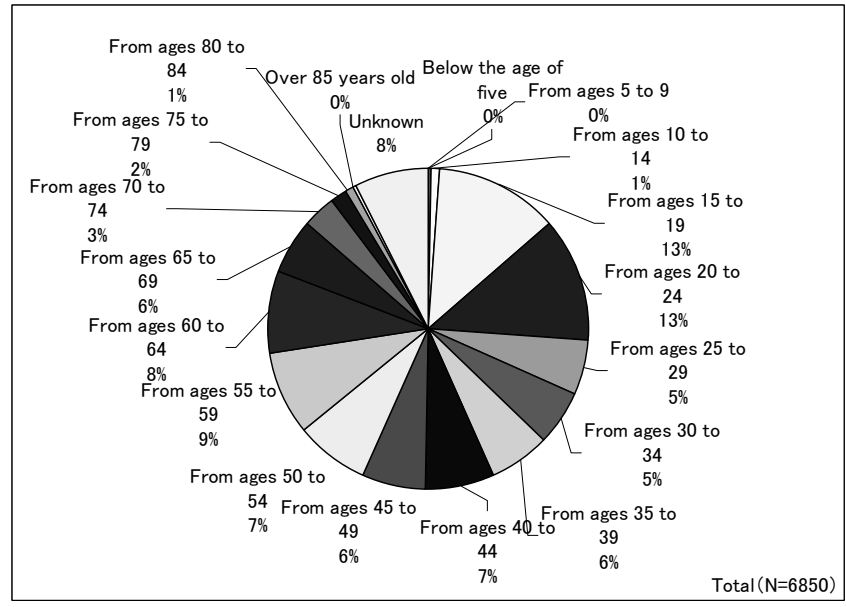

Fig.6 The age of users

On the age of the users, the age between 15 and 19 accounted for $13 \%$, between 20 and 24 years old accounted for $13 \%$, the age between 55 and 59 accounted for $9 \%$, the age between 60 and 64 accounted for $8 \%, 40-44,50-54$ separately accounted for $7 \%$, over the age of 65 accounted for $12 \%$.

\subsection{JR connection}

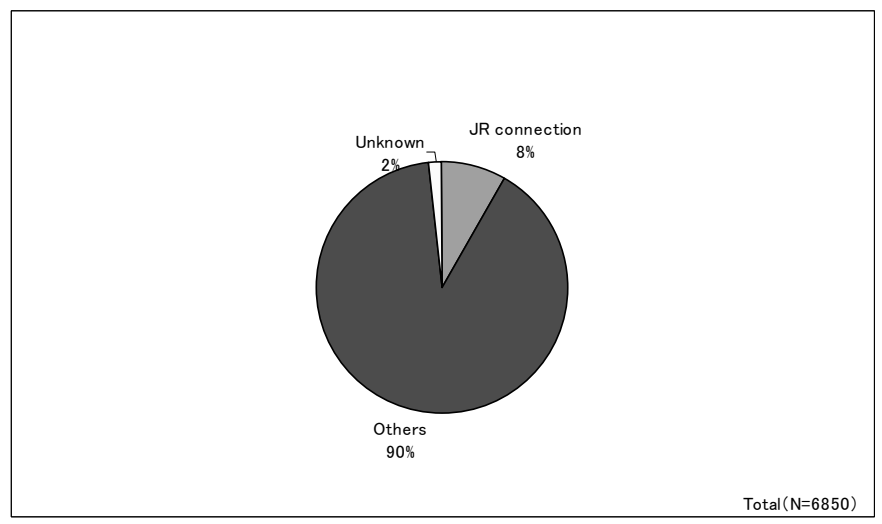

Fig.7 JR connection

In the JR connection, JR connection accounted for $13 \%$, and others accounted for $90 \%$.

\section{The demographic transition and population predictions along the monorail}

\section{from 2004 to 2009, the prediction on the population's} coefficient of increase and decrease along the various stations of the monorail

From the decade from 1999 to 2009, the population along the monorail is around 86,251 to 86,228 , basically unchanged the proportion of the age over 65 years increased from $14 \%$ to $19 \%$.

The five years from 2004 to 2009, alongside the area of monorails, the population has been reduced from 86,992 to 86,228 . Among the reduced population, the old over 65 years have increased from $16 \%$ to $19 \%$. Next five years from 2009 to 2014, the population in each age bracket increase or decrease according to the same number, we could predict the population in 2014, the population over the age of 5 using the formula1, the population under 5 using the formula2

$\mathbf{P}_{14}=\mathbf{P}_{14 \mathrm{M}}-\left(\mathbf{P}_{\mathbf{0 9 M}}-\mathbf{P}_{09}\right) \times \mathbf{P}_{14 \mathrm{M}} / \mathbf{P}_{\mathbf{0 9 M}} \quad$ (formula1)

$\mathbf{P}_{14}=\mathbf{P}_{09}+\left(\mathbf{P}_{09}-\mathbf{P}_{04}\right) \quad$ (formula2)

However. 
$\mathbf{P}_{14}$ : The population of 2014 (prediction)

$\mathbf{P}_{\mathbf{0 9}}$ : The population of 2009

$\mathbf{P}_{14 M}$ : A value when the population of whole just changes for five years in 2009

$\mathbf{P}_{\mathbf{0 9 M}}$ : A value when the population of whole just changes for five years in 2004

Furthermore, we could use the above formula to predict the population between 2019 and 2024 in each age bracket alongside the area of monorails.

According to the prediction, the decade from 2009 to 2019 , the population would have been reduced from 86,228 to 81,924 alongside the area of monorails, among the data, the number of people over the age of 65 would have been increased from $19 \%$ to $24 \%$.

Apart from the demographic speculation of 5 years interval, we also speculated the interval of 10 years and 15 years, the result is generally the same.

According to the above speculations, from now on till 2019 , the population alongside the area of monorail would have been reduced by approximately $5 \%$, entering the aging society.

Figure 8 shows the information of demographic predictions alongside the area of monorail during the year 2004, 2009, 2014 and 2019.The total population alongside the monorail is divided by the age braket of 5 . Dark figures in the demographic diagram shows the age bracket of more than 6,000. From the population of all age brackets in 2004, the population between 30-year-old and 34-year-old people is the most, approximately 7839 people. From the data of 2009 , the population of the age bracket between the 35-year-old and 39-year-old people is the most.
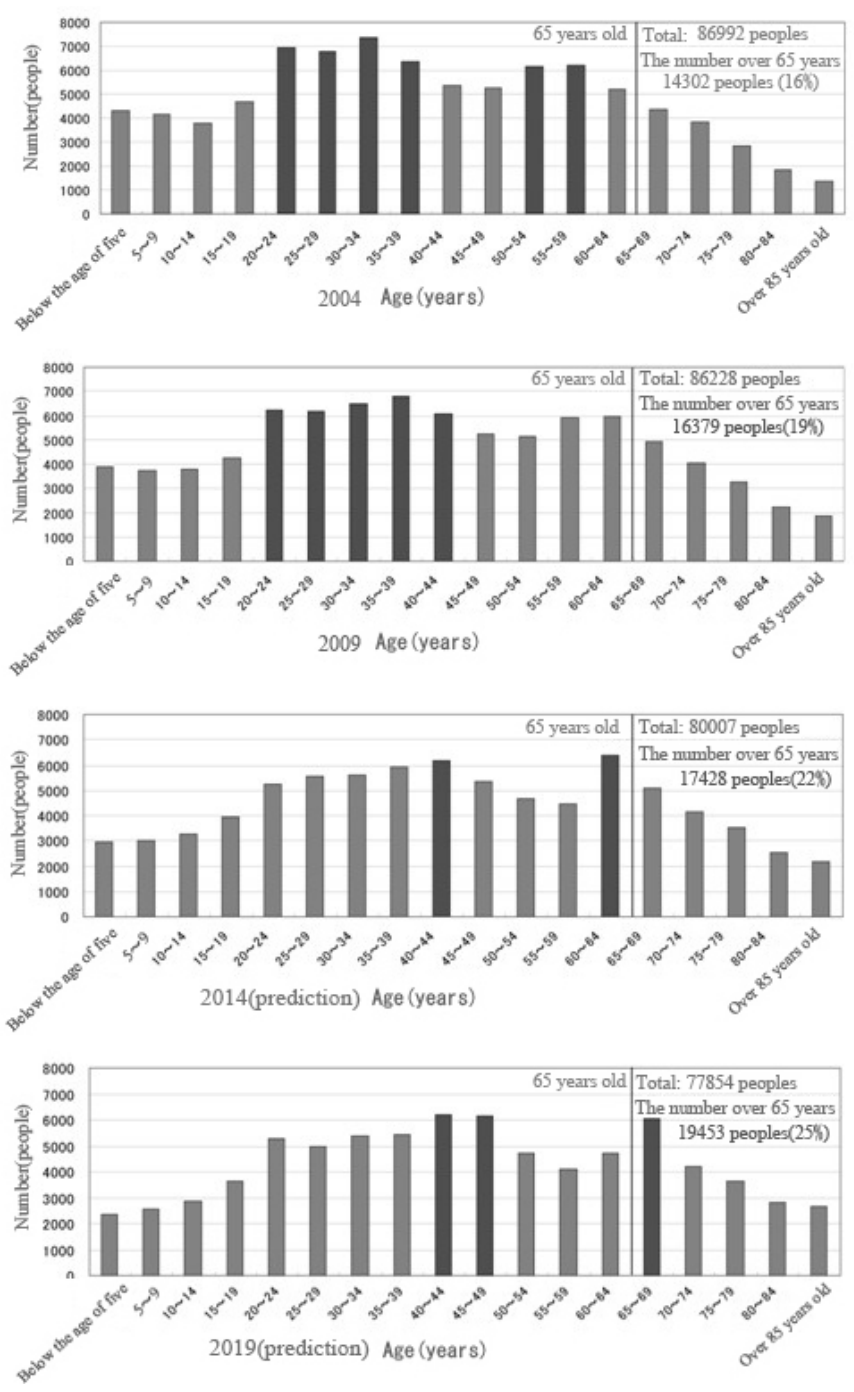

Fig.8 The information of demographic predictions alongside the area of monorail during the year 2004, 2009, 2014 and 2019

Figure 9 shows the population alongside the area of monorails between the year 1999 and 2009 and the demographic predictions of 2019. The decade from 2009 to 2019 , the total number decreased by $3.5 \%$. The predicted results of the past decade and the past 5 years are basically the same.The ratio of the elderly people in 2019 increased to $25 \%$. 

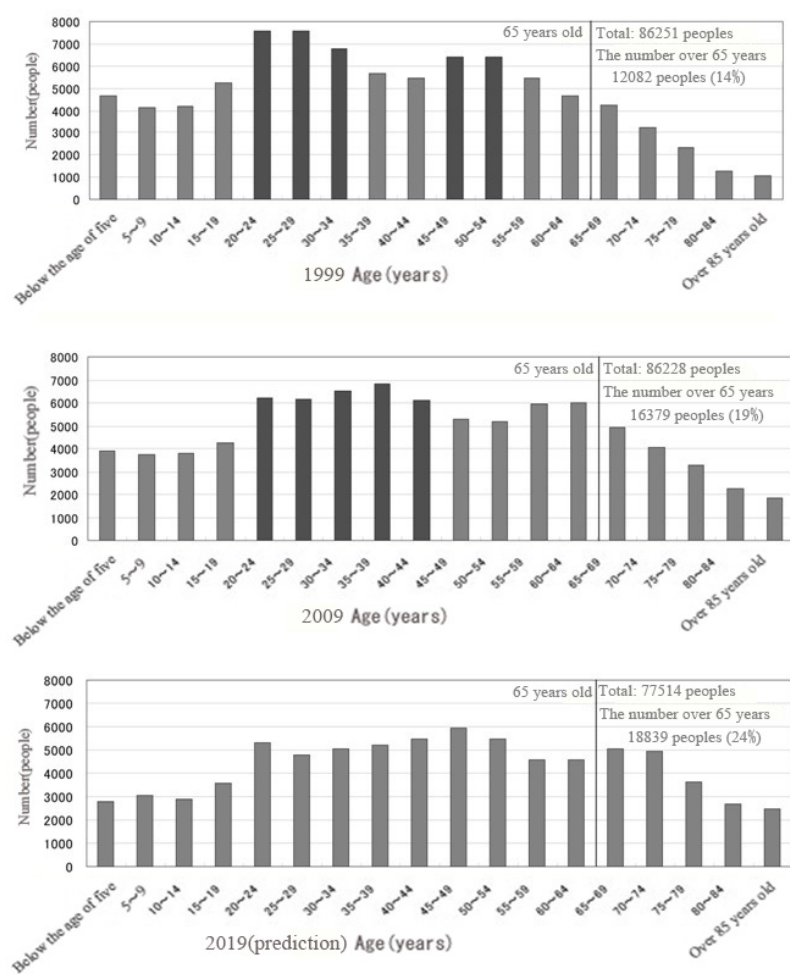

Fig.9 The population alongside the area of monorails between the year 1999 and 2009 and the demographic predictions of 2019

Figure 10 shows the demographic predictions alongside the area of monorails in all age brackets during the year 2019 and 2024.The predicted methods of intervals of 5 and 10 years are almost the same results. During the fifteen years from 2009 to 2024, the total population decreased by $1.2 \%$.

In the future the population alongside the area of monorails would have been decreased by $5 \%$ approximately in 2019, aged tendency of population is about $25 \%$.One in four is the elderly people.From the tendency result of the population alongside the monorails, which brings more and more pressure to the public transportation.

\section{CONCLUSIONS}

This study is about the investigation of the users' condition in kokura alongside the monorails. We carried
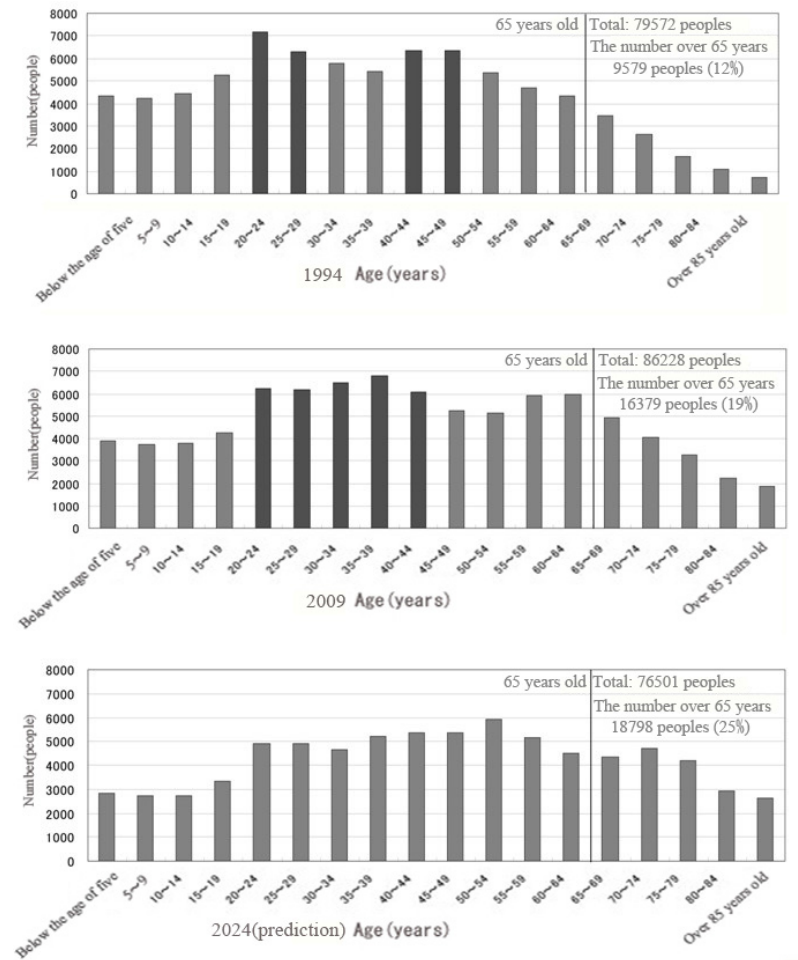

Fig.10 The demographic predictions alongside the area of monorails in all age brackets during the year 2019 and 2024

out the demographic predictions about the demographic status and the demographic composition of the future alongside the area of monorails. According to the predictions for the rapid increase in aging, we should consider the problem of the elderly in improving the fractfture around the station, including when improving the public transportation we should also consider the infrastructure to be more convenience.

\section{REFERENCE}

[1]Wikipedia

http://en.wikipedia.org/wiki/Kitaky\%C5\%ABsh\%C5\%AB_M onorail

[2] Two Future One Choice, 1998, Christchurch City council

[3]Developing Urban Transport Strategies through Package Approaches, 2010

[4]The Institute of Highways and Transportation: Guidelines for Developing Urban Transport Strategies, HMSO, 1996 